\title{
Radiant realms
}

\section{Philip Ball enjoys two explorations of light, spanning wonders from Newton's spectrum to the aurora borealis.}

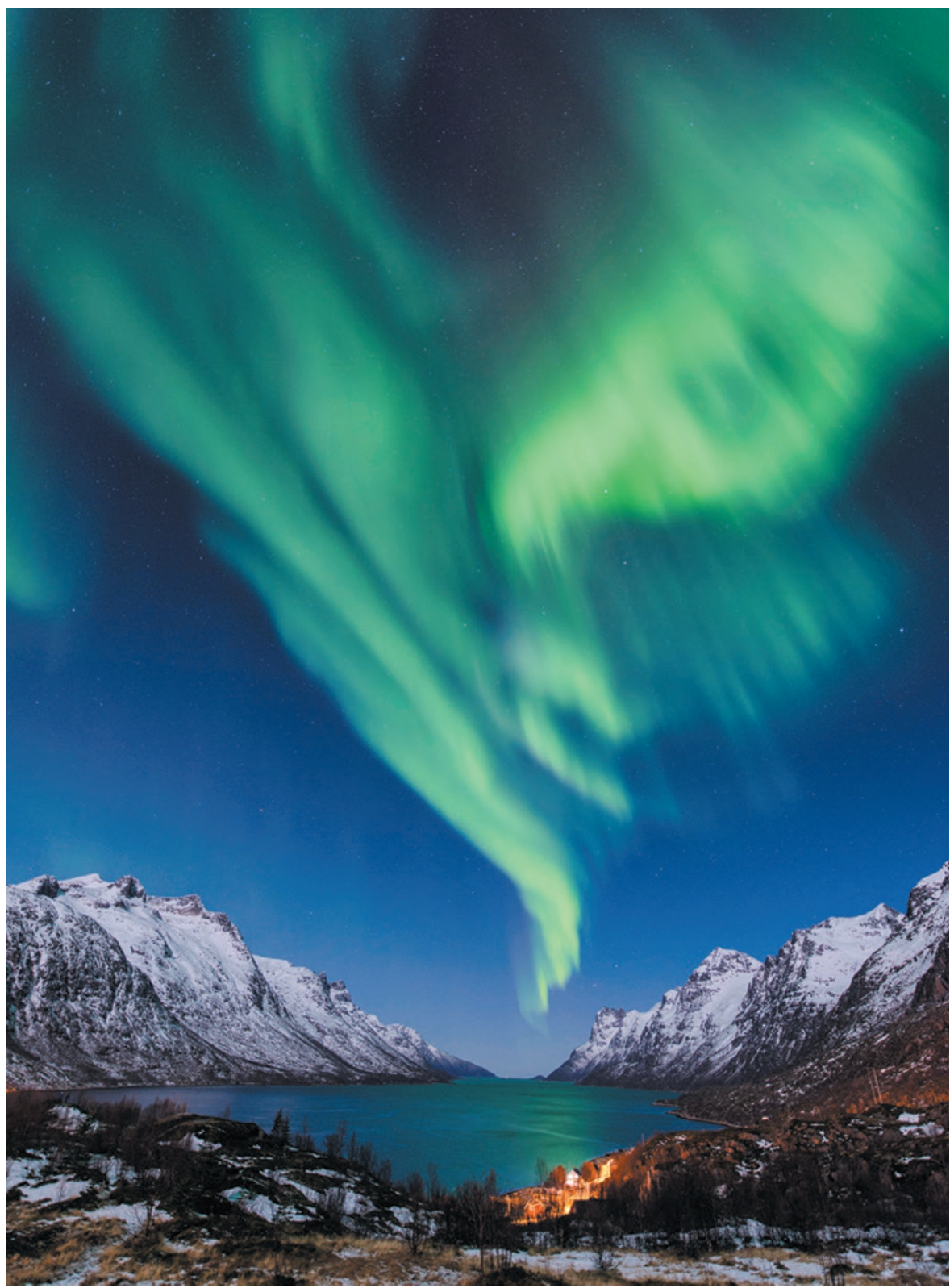

The northern lights over Norway — produced by the solar wind and Earth's magnetic field.

$\mathrm{L}$ ast year's International Year of Light is now history, but light remains high on the scientific agenda. From photosynthesis to quantum optics and light-emitting organic compounds, there is no getting away from it, even if you wanted to. Bruce Watson's Light and Melanie Windridge's Aurora - one encyclopaedic, the other more focused - are as eloquent about the aesthetic pleasures of light as they are about the scientific issues that it presents. The temptation to call them lucid and illuminating only highlights (there I go again) the linguistic currency of this fundamental phenomenon.

In Light, Watson offers a wide-ranging tour of the cultural, literary and scientific response to his subject. Our associations with light seem almost unrelentingly favourable. Light is divine, dark demonic. "God Appears \& God is Light/To those poor Souls who dwell in
Night", wrote William Blake in 1803, in 'Auguries of Innocence.' What could seem more natural than this dualism? We have sought for centuries to understand and use light, and never stopped worshipping it. Watson seems to acknowledge that by bookending his study with contemporary sunrise ceremonies at the prehistoric stone monuments of Stonehenge in England and Newgrange in Ireland.

The stops along the way will surprise no one who has a passing acquaintance with the traditions and science of light. The dazzling list includes creation myths, Aristotle's meditations on vision and ether, the light metaphysics of medieval Neoplatonism that identified God with radiance and informed Gothic architecture, the tonal contrast of light and dark (chiaroscuro) developed by Leonardo da Vinci, the work of earlymodern scientists from Johannes Kepler to Isaac Newton, polymath Thomas Young's wave theory of 1800 , painter J. M. W. Turner's last words ("The Sun is God"), Thomas Edison's light bulb, Albert Einstein's quanta and the laser. Even when covering familiar ground, Watson's touch is lyrical and deft.

Romantic poet John Keats famously declared in his 1884 epic poem Lamia that the progression from uncomprehending wonder to scientific understanding had unwoven the rainbow. He underestimated light's enduring appeal. Light might now be just a little slice of a continuous electromagnetic spectrum; trapped in optical fibres and sent hither and thither at our bidding; chopped into quanta and parted into electrical and magnetic oscillations. But it has not lost its primeval power to enchant. Modern artists make astonishing light sculptures, from James Turrell's subliminal illusions to Carlos Cruz-Diez's disorienting chromatically saturated light-rooms. Coloured light is still used to summon contemplation, as seen in the stained glass of Henri Matisse's midtwentieth-century Chapel of the Rosary in Vence, France. And the crowds that Watson joined at Neolithic monuments are not hippie throwbacks. They are simply people eager to experience the awe of a primal event - the appearance of the Sun's first rays.

In any case, it is foolhardy to assert that light is scientifically understood. It is more like a beam guiding us to deeper mysteries. Newton's experiment with prisms in a "darken'd chamber" to reveal the spectrum of sunlight is often presented as a turning point, celebrated by Alexander Pope in his 'Epitaph on Sir Isaac Newton': "Nature and Nature's Laws lay hid in Night/God said, "Let Newton be!" and all was light." But physicists including Young, James Clerk Maxwell and Einstein all radically altered Newton's picture - a picture that is still shifting, with the use of quantum optics to explore the fundamentals of quantum theory and reveal the strange connections that may persist between photons. 


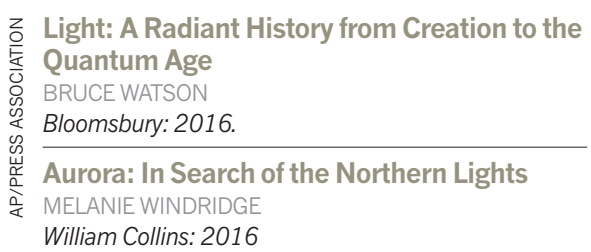

Watson's book is an eye-catching display, reflecting and refracting like a gemstone. One moment we are among late-nineteenth-century Parisians watching the cinematograph of the Lumière brothers (was there ever a better example of nominative determinism?). The next we are examining Rembrandt's 1642 painting The Night Watch - which depicts a militia emerging into the light - or commiserating with modern astronomers about light pollution. This is all tremendous fun, but never quite focuses into a coherent image. Perhaps light has too many facets to offer unifying themes. However, like other mythologically charged substances (such as water and gold), it does not easily shed its associations under scientific scrutiny. That may be why transformation optics has become a 'technology of invisibility' and quantum optics claims to promise teleportation. The electromagnetic ether was once considered a possible bridge between the physical and spiritual worlds; in a way, light still holds that allure.

Nowhere is that more apparent than in the phenomenon of the aurora borealis, or northern lights, produced when subatomic particles in the solar wind collide with molecules in the atmosphere at Earth's magnetic pole, stimulating emissions of light. Plasma physicist Melanie Windridge embraces the aurora's magical quality even as she attempts to unravel the science. She has camped at temperatures approaching $-40^{\circ} \mathrm{C}$ in Svalbard,

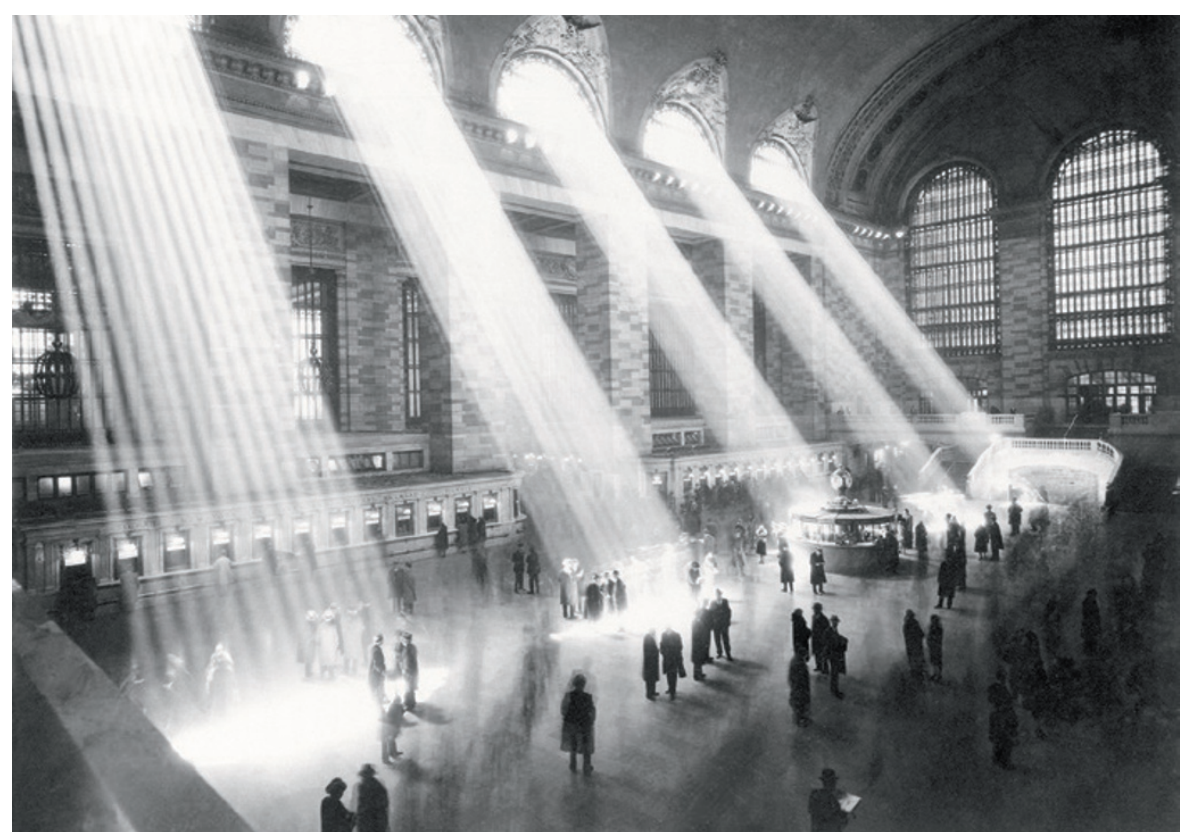

Sunlight streaming through windows at New York City's Grand Central Terminus.

Norway's Arctic archipelago, to experience the visceral thrill of seeing these shimmering curtains. It is clear in this captivating book that her technical understanding has not dimmed her delight.

Windridge's account explains what we do and do not yet know about the auroras, and how this understanding has evolved. The journey takes in the restless, violent activity of the Sun's outer layers, the physics of interaction between the plasma of the solar wind and Earth's magnetic field, the atomic physics that generates the various colours of the aurora (oxygen produces the predominant green and red, nitrogen the rarer blue and purple) and the potential of auroral monitoring (for instance, of changes in shape) to provide advance warning of disruption to telecommunications caused by stormy "space weather".

What emerges is the tremendous difficulty of formulating intuitive and predictive models of a turbulent and chaotic process. The auroral morphologies are described even now in qualitative terms - arcs, veils, rays and so forth - and a full theory is still lacking. Windridge makes a persuasive case that the quest to find one is both pragmatic and inspired by the visual majesty of nature's light.

Philip Ball is a writer based in London. His latest book is Invisible.

e-mail:p.ball@btinternet.com

\section{Broken bridges and highways from hell}

\section{Kyle Shelton applauds a study that probes the parlous state of US infrastructure.}

$\mathrm{I}$ n The Road Taken, engineer and historian Henry Petroski surveys the state of US bridges, roads and tunnels - the legacy of two centuries of technological development - and finds them crumbling. Echoing Robert Frost's poem 'The Road Not Taken', Petroski reflects on both physical highways and the choices that contributed to their current state. As Frost wrote, "Two roads diverged in a wood, and I-/I took the one less traveled by,/And that has made all the difference." Petroski compellingly shows that only by closely investigating the figurative roads down which the country has travelled,

and the decisions made at their forks, can the past be used to shape the future.

Some of those paths, he reveals, have been revolutionary - from the advent of asphalt for road construction in 1870 to the quest for autonomous cars. Some have thrown up obstacles that affect future choices: expensive projects, huge maintenance demands,

$\checkmark$ NATURE.COM For more on science in culture see: nature.com/ booksandarts short-sighted political decisions and lacklustre design. Petroski shows how the choices of policymakers and engineers contributed to soaring successes such as the Golden Gate Bridge in San Francisco, California, and tragic failures including the 2007 collapse of the I-35W bridge in Minneapolis, Minnesota, which killed 13 and injured 145 .

A typical history of US transport infrastructure would begin with the travel revolution of the early nineteenth century. This spawned the steamship, New York's Erie Canal and the first federally funded highway, the National Road. Then followed railways, bicycles and the early-twentieth-century boom in automobiles and road construction.

Petroski touches on much of this, as well as 